\title{
Diversidade genética em cultivares locais e comerciais de feijão baseada em marcadores RAPD(1)
}

\author{
Beatriz Marti Emygdio(2), Irajá Ferreira Antunes ${ }^{(3)}$, Jorge Luiz Nedel(4) e Eva Choer ${ }^{(3)}$
}

Resumo - O objetivo deste trabalho foi caracterizar a diversidade genética dentro e entre cultivares locais e comerciais de feijão, por meio de marcadores RAPD, e avaliar a capacidade destes em agrupar genótipos de feijão de acordo com o centro de domesticação e coloração de semente. Foram avaliadas 35 cultivares, 13 comerciais e 22 locais, de diversas regiões do Rio Grande do Sul. As distâncias genéticas foram obtidas pelo complemento do coeficiente de similaridade de Sorensen-Dice e a representação simplificada destas distâncias realizada mediante um dendrograma. Marcadores RAPD foram eficientes ao agrupar cultivares de acordo com o centro de domesticação, mas não foram capazes de separar as cultivares de acordo com a coloração da semente. Cultivares locais e comerciais, mesoamericanas, foram agrupadas separadamente. Cultivares comerciais, em cultivo no Rio Grande do Sul apresentam alto grau de similaridade.

Termos para indexação: Phaseolus vulgaris, variação genética, análise de agrupamento.

\section{Genetic diversity in cultivars and landraces of common bean based on RAPD markers analysis}

\begin{abstract}
The objective of this work was to characterize the genetic diversity within and among cultivars and landraces of common bean from RAPD markers analysis, and to evaluate the capacity of this markers in clustering common bean genotypes according to domestication centers and seed color. Thirty five common bean genotypes including 13 commercial cultivars and 22 landraces, from State of Rio Grande do Sul, Brazil, were evaluated. Genetic distances were calculated using Sorensen-Dice's similarity coefficient, displayed in a dendrogram. RAPD markers were efficient in separating cultivars and landraces according to domestication centers, but not according to seed color. Mesoamerican commercial cultivars and landraces have been clustered in different groups. A high degree of similarity was observed among cultivars in use in Rio Grande do Sul.
\end{abstract}

Index terms: Phaseolus vulgaris, genetic variation, cluster analysis.

\section{Introdução}

Cultivares melhoradas, denominadas cultivares comerciais neste estudo, e cultivares locais

(1) Aceito para publicação em 18 de agosto de 2003 .

Extraído da tese de doutorado apresentada pelo primeiro autor à Universidade Federal de Pelotas (UFPel), Pelotas, RS.

(2) Embrapa-Centro Nacional de Pesquisa de Trigo, Caixa Postal 451, CEP 99001-970 Passo Fundo, RS. E-mail: bemygdio@cnpt.embrapa.br

(3) Embrapa-Centro de Pesquisa Agropecuária de Clima Temperado, Caixa Postal 403, CEP 96001-970 Pelotas, RS. E-mail: iraja@cpact.embrapa.br, choer@cpact.embrapa.br

(4)UFPel, Fac. de Agronomia, Caixa Postal 354, CEP 96010-900 Pelotas, RS. E-mail: jlnedel@ufpel.tche.br (landraces), tradicionalmente cultivadas por pequenos agricultores, constituem o pool gênico primário, disponível para hibridização em programas de melhoramento (Harlan \& De Wet, 1971). O conhecimento da diversidade genética entre as cultivares comerciais e entre estas e as locais é extremamente útil aos melhoristas, por permitir melhor organização dos recursos genéticos e melhor aproveitamento da diversidade genética disponível.

Cultivares de feijão são freqüentemente divididas em dois grandes grupos, com base, principalmente, no tipo de proteína de reserva (Gepts et al., 1986; Gepts \& Bliss, 1986), variação isoenzimática (Singh et al., 1991b) e tamanho de semente (Singh et al., 1991a). Estes grupos representam os pools 
gênicos andino e mesoamericano, que correspondem a centros de domesticação independentes (Gepts et al., 1986).

Recentemente, diversos autores (Nienhuis et al., 1995; Vasconcelos et al., 1996; Johns et al., 1997; Cattan-Toupance et al., 1998; Vera et al., 1999; Beebe et al., 2000; Eichenberg et al., 2000) têm demonstrado que marcadores RAPD são capazes de separar genótipos de feijão de acordo com o centro de domesticação.

Tradicionalmente, a diversidade genética em feijão tem sido avaliada por meio de marcadores morfológicos, tais como hábito de crescimento, tipo de semente, resistência a doenças e pragas (Singh et al., 1991a). Entretanto, esses marcadores são afetados pela ação gênica de dominância, efeito ambiental, pleiotropia e epistasia, tornando menos estáveis suas caracterizações.

Marcadores moleculares têm demonstrado eficácia na avaliação da variabilidade genética dentro e entre populações de plantas e na elucidação de parentescos entre acessos dentro de uma espécie. Nos programas de melhoramento, a informação da diversidade genética dentro de uma espécie é essencial. É particularmente útil na caracterização individual dos acessos e cultivares e como guia na escolha dos pais em programas de cruzamento (Loarce et al., 1996).

Bai et al. (1998) verificaram a eficiência de marcadores RAPD em detectar grau de parentesco entre genótipos de feijão, mediante análise de um esquema de cruzamentos e comparação com o coeficiente de parentesco.

Mediante marcadores RAPD, Beebe et al. (1995) constataram que feijões com sementes pretas e vermelhas, intimamente aparentados, da América Central, formam dois grupos distintos. Da mesma forma, marcadores moleculares foram eficientes na distinção de cultivares locais de feijão oriundas de um mesmo local (Puebla) e na distinção entre estas e as populações selvagens de feijão (González et al., 1998).

O objetivo deste trabalho foi caracterizar a diversidade genética dentro e entre cultivares locais e comerciais de feijão por meio de marcadores RAPD e avaliar a capacidade destes marcadores em agrupar genótipos de feijão de acordo com a coloração de semente e centro de domesticação.

\section{Material e Métodos}

Foram analisadas 22 cultivares locais de feijão coletadas em diversas regiões do Rio Grande do Sul, sendo 19 de grãos pretos e três de grãos de duas cores, e 13 cultivares comerciais, sendo nove de grãos pretos e quatro de grãos de duas cores (Tabela 1).

As amostras de sementes, em sua maioria, apresentaram variabilidade fenotípica. Procedeu-se à classificação das sementes em subamostras quanto ao tamanho, forma e coloração. O padrão predominante foi multiplicado em campo, sob as mesmas condições ambientais, e constituiu a amostra de trabalho.

O DNA genômico foi extraído a partir de dez plantas por genótipo, distribuídas em duas amostras de 120 mg de

Tabela 1. Cultivares locais e comerciais de feijão (Phaseolus vulgaris L.) incluídas no estudo de diversidade genética por meio de marcadores RAPD.

\begin{tabular}{|c|c|c|c|}
\hline \multirow[t]{2}{*}{ Cultivar } & \multirow{2}{*}{$\begin{array}{c}\text { Centro de } \\
\text { domesticação }\end{array}$} & \multicolumn{2}{|c|}{ Semente } \\
\hline & & Cor & Peso $(g)^{(1)}$ \\
\hline \multicolumn{4}{|c|}{ Locais } \\
\hline 05 OPPP & Mesoamericano & Preta & 14,4 \\
\hline 06 OPM & Mesoamericano & Preta & 16,5 \\
\hline 14 OPMP & Mesoamericano & Preta & 17,8 \\
\hline 15 OPEN & Mesoamericano & Preta & 15,5 \\
\hline $24 \mathrm{OP}$ & Mesoamericano & Preta & 13,9 \\
\hline $25 \mathrm{BRM}$ & Mesoamericano & Preta & 18,6 \\
\hline 26 OPP & Mesoamericano & Preta & 14,6 \\
\hline 30 OPР & Mesoamericano & Preta & 13,9 \\
\hline 36 BRMP & Andino & Preta & 35,7 \\
\hline $39 \mathrm{BR}$ & Andino & Preta & 34,0 \\
\hline $42 \mathrm{AM}$ & Andino & Vinho & 32,7 \\
\hline $45 \mathrm{MO}$ & Andino & Cinza/preta ${ }^{(2)}$ & 32,9 \\
\hline 54 OPM & Mesoamericano & Preta & 15,7 \\
\hline 55 OPEN & Mesoamericano & Preta & 15,3 \\
\hline $56 \mathrm{OP}$ & Mesoamericano & Preta & 19,2 \\
\hline $57 \mathrm{OP}$ & Mesoamericano & Preta & 15,6 \\
\hline 58 OPP & Mesoamericano & Preta & 15,0 \\
\hline 60 OPP & Mesoamericano & Preta & 18,9 \\
\hline 60 OPM & Mesoamericano & Preta & 17,3 \\
\hline 61 OPP & Mesoamericano & Preta & 17,3 \\
\hline $61 \mathrm{OPM}$ & Mesoamericano & Preta & 19,5 \\
\hline $62 \mathrm{MO}$ & Andino & Vermelha/preta ${ }^{(2)}$ & 35,2 \\
\hline \multicolumn{4}{|c|}{ Comerciais } \\
\hline Rio Tibagi & Mesoamericano & Preta & 13,6 \\
\hline Guateian 6662 & Mesoamericano & Preta & 13,7 \\
\hline Macanudo & Mesoamericano & Preta & 15,3 \\
\hline Minuano & Mesoamericano & Preta & 18,6 \\
\hline Iapar 44 & Mesoamericano & Preta & 16,8 \\
\hline Macotaço & Mesoamericano & Preta & 13,3 \\
\hline Guapo Brilhante & Mesoamericano & Preta & 8,2 \\
\hline FT Nobre & Mesoamericano & Preta & 18,1 \\
\hline FT 120 & Mesoamericano & Preta & 16,2 \\
\hline Carioca & Mesoamericano & Creme/havana $^{(2)}$ & 20,7 \\
\hline Iraí & Andino & Areia/vinho ${ }^{(2)}$ & 37,6 \\
\hline FT 206 & Mesoamericano & Creme/havana $^{(2)}$ & 19,1 \\
\hline Iapar 31 & Mesoamericano & Creme/havana ${ }^{(2)}$ & 19,8 \\
\hline
\end{tabular}


tecido foliar. As folhas foram maceradas em nitrogênio líquido e o DNA foi extraído com base no protocolo descrito por Ferreira \& Grattapaglia (1998). As reações de amplificação foram realizadas em um termociclador modelo RoboCycler 96 - Temperature Cycler, programado para 39 ciclos repetidos de $94^{\circ} \mathrm{C}$ por 15 segundos (desnaturação), $35^{\circ} \mathrm{C}$ por 30 segundos (anelamento) e $72^{\circ} \mathrm{C}$ por 1 minuto (extensão). Após, foi realizado um ciclo adicional de extensão a $72^{\circ} \mathrm{C}$ por 1 minuto.

Os produtos das reações de amplificação foram separados eletroforeticamente em gel de agarose, horizontal, na concentração de $1,4 \%$, aplicando-se 120 volts, com um tempo de corrida de três horas. Os géis foram corados com brometo de etídio, na concentração de 7,5 $\mu \mathrm{L}$ de uma solução de $10 \mathrm{mg} \mathrm{mL}^{-1}$ para cada gel de $150 \mathrm{~mL}$. As bandas de DNA foram visualizadas e fotografadas sob luz ultravioleta.

Um total de 96 primers, provenientes dos kits OPA, OPC, OPI, OPY e OPX (Operon Technologies, Alameda, CA) e do kit 1-200 do Canadá foram utilizados para a triagem. Destes, foram selecionados sete (OPA-02, OPI-03, OPI-06, OPI-07, OPY-20, 135 e 173) por sua resolução, polimorfismo e repetibilidade.

As bandas de DNA obtidas no processo de amplificação foram analisadas de forma binária pela presença (1) ou ausência (0), construindo-se desta maneira uma matriz de dados. A estimativa da similaridade genética entre os genótipos foi feita pelo coeficiente de similaridade, utilizando-se o coeficiente de Sorensen-Dice. A análise de agrupamento dos materiais foi efetuada pelo método de média aritmética não ponderada (UPGMA) e agrupamento seqüencial, aglomerativo, hierárquico e exclusivo (SAHN), segundo o programa NTSYS (Numerical Taxonomy and Multivariate System) versão 1.7 (Rohlf, 1992).

\section{Resultados e Discussão}

A partir dos sete primers utilizados obteve-se um total de 104 bandas, das quais 85,6\% foram polimórficas e 14,4\% monomórficas, com uma média de 14,9 bandas por primer. Resultados semelhantes foram observados por Vera et al. (1999), a partir de 38 primers, obtendo 83,2\% de bandas polimórficas e $16,8 \%$ de bandas monomórficas.

Nienhuis et al. (1995) demonstraram em feijão que, com número de bandas igual ou superior a 100, o coeficiente de variação das distâncias genéticas entre os genótipos estabiliza. De forma mais drástica,
Johns et al. (1997) em estudo com 60 cultivares chilenas de feijão observaram que 50 bandas escolhidas ao acaso produziram o mesmo agrupamento que 106 bandas.

A análise das distâncias genéticas, obtidas a partir de marcadores RAPD, evidencia o agrupamento das cultivares locais e comerciais de acordo com seus respectivos centros de domesticação, andino e mesoamericano, formando dois grandes grupos. A divergência genética entre estes dois grupos, segundo o coeficiente de Sorensen-Dice, é de 38\% (62\% de similaridade) (Figura 1), valor intermediário aos observados por Mienie et al. (2000), 26\%, e por Franco et al. (1998), 55\%, com outro grupo de genótipos.

Outros autores também verificaram a eficiência de marcadores RAPD em separar genótipos de feijão pertencentes ao pool gênico andino dos pertencentes ao pool gênico mesoamericano (Nienhuis et al., 1995; Vasconcelos et al., 1996; Johns et al., 1997; Cattan-Toupance et al., 1998; Duarte et al., 1999; Beebe at al., 2000). No entanto, Vilarinhos et al. (1995) estudando cultivares de feijão de origem andina e mesoamericana, por meio de marcadores RAPD, e Rodrigues (2001), mediante características morfológicas, não verificaram tal agrupamento.

A variabilidade genética dentro de cada um dos grupos (andino e mesoamericano) é relativamente restrita. Os genótipos do grupo andino apresentaram similaridade superior a $75 \%$ e os do grupo mesoamericano, similaridade superior a $65 \%$, quando considerada a cultivar 25 BRM, e superior a $82 \%$ entre as outras 28 cultivares incluídas neste grupo (Figura 1).

Tais valores, ainda que representem alta similaridade entre as cultivares, dentro de cada grupo, são inferiores aos valores encontrados por Franco et al. (1998), aproximadamente $80 \%$ de similaridade para o grupo andino e $85 \%$ para o mesoamericano, e por Mienie at al. (2000), aproximadamente 88\% para ambos os grupos.

As maiores distâncias foram obtidas entre cultivares pertencentes aos diferentes centros de domesticação (Tabela 2). Duarte et al. (1999) obtiveram resultados semelhantes. A menor distância observada foi entre cultivares mesoamericanas, sendo as maiores entre cultivares de diferentes centros de domesticação. Esses resultados confirmam a exis- 


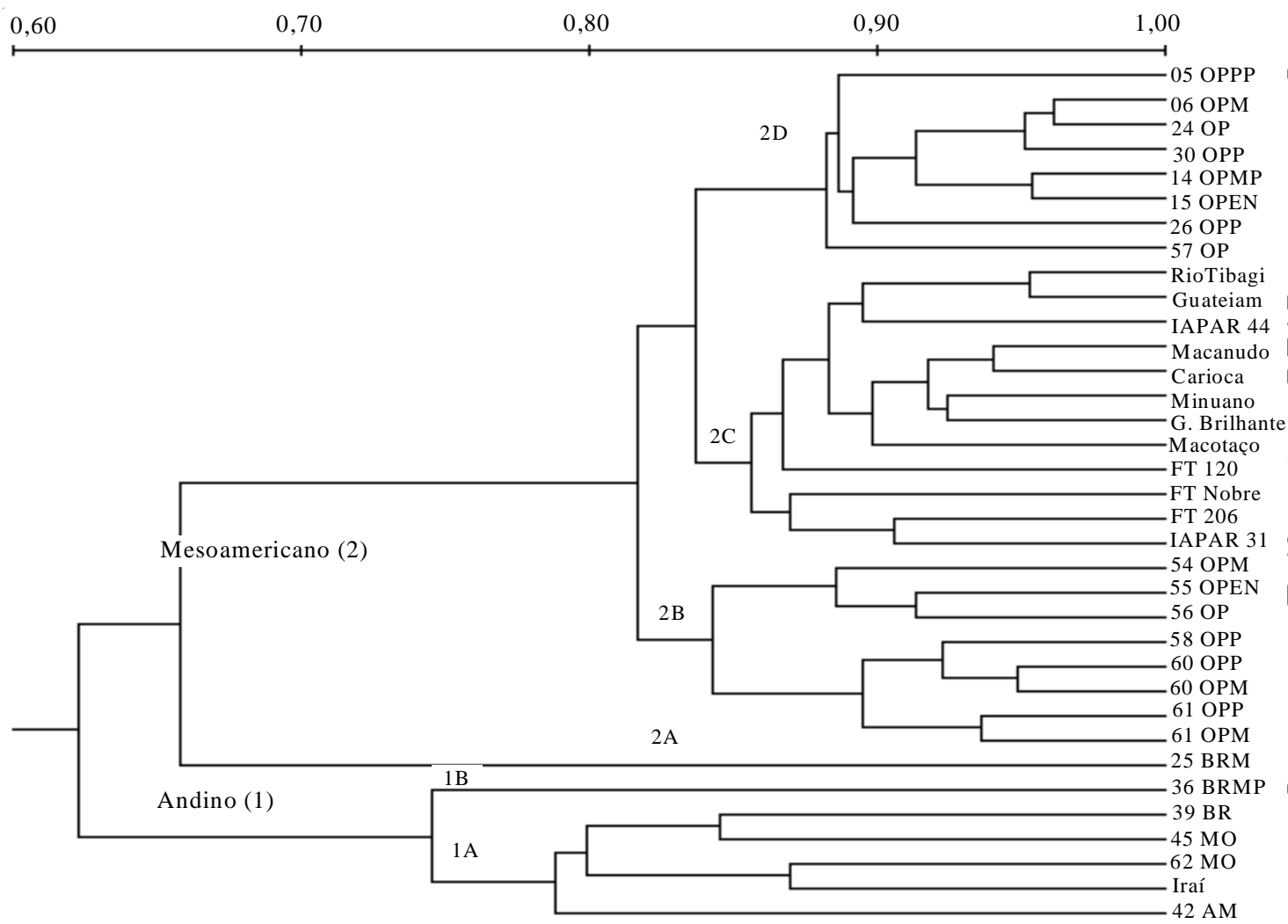

Figura 1. Dendrograma de 35 cultivares de feijão indicando as relações genéticas e a porcentagem de similaridade obtida a partir do coeficiente de Sorensen-Dice.

tência de considerável diferenciação genética entre cultivares pertencentes aos diferentes centros de domesticação, já observada por Haley et al. (1994) e Vasconcelos et al. (1996), embora, quando a comparação é feita entre os grupos, a divergência é de 38\%.

Dentro do pool gênico mesoamericano, que agrupa 29 cultivares, 17 locais e 12 comerciais, é possível distinguir quatro subgrupos, 2A, 2B, 2C e 2D (Figura 1).

O subgrupo 2C, que compreende todas as cultivares comerciais incluídas neste estudo, com exceção de Iraí, que é uma cultivar andina, apresenta similaridade entre $86 \%$ e $95 \%$ (Figura 1). Esses resultados evidenciam a recorrência às mesmas fontes de germoplasma no desenvolvimento de cultivares em programas de melhoramento na Região Sul do Brasil, embora as cultivares analisadas apresentem considerável variação quanto a algumas características morfológicas, como tipo de planta, coloração e tamanho de sementes.

De forma contrastante, Rodrigues (2001), utilizando exclusivamente características morfológicas, verificou o agrupamento de cultivares com sementes de duas cores, tanto locais quanto comerciais e de ambos os centros de domesticação, em um único grupo. As cultivares Carioca, FT 206 e IAPAR 31, mesoamericanas, com sementes de cor areia/creme, foram agrupadas com Iraí, andina, de sementes areia/ vinho.

Duarte et al. (1999), utilizando marcadores RAPD, verificaram entre cultivares mesoamericanas tendência ao agrupamento com base na coloração da semente. Cultivares com sementes de cor bege e cultivares com sementes pretas formaram subgrupos distintos. Beebe et al. (1995) também observaram agrupamento independente entre cultivares com semen- 

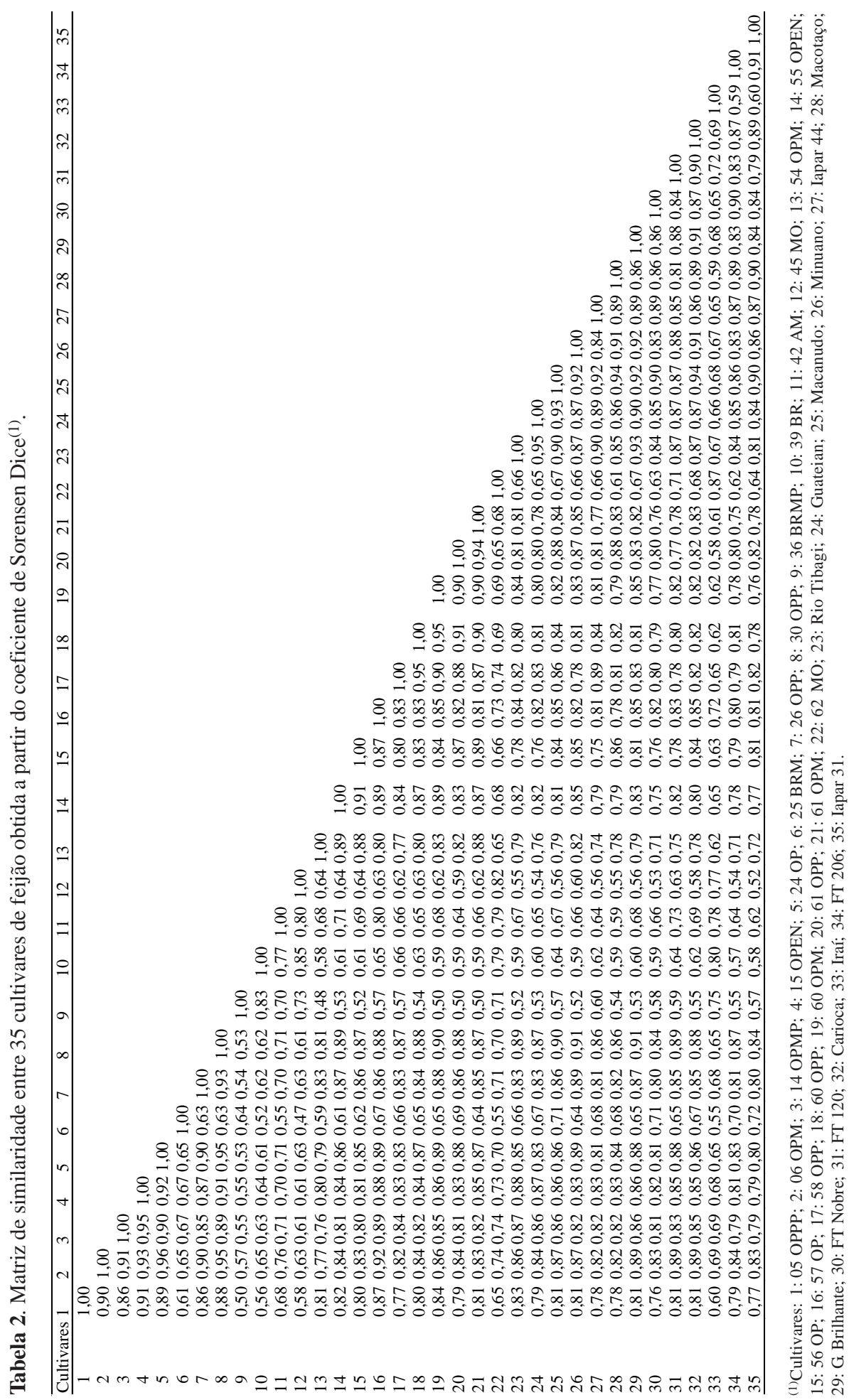
tes de cor vermelha e cultivares com sementes de cor preta. Alvarez et al. (1998), por meio de marcadores RAPD e isoenzimáticos, não encontraram correspondência entre o agrupamento de cultivares locais de feijão e características morfológicas da semente, como coloração, tamanho e formato, comumente utilizadas para caracterizar cultivares locais. Cultivares com padrão de tamanho e coloração contrastantes apresentaram as maiores porcentagens de similaridade.

O subgrupo 2A compreende exclusivamente a cultivar 25 BRM. Esta cultivar apresentou poder germinativo de apenas 42,7\%, além de semente dura, o que parece justificar sua discrepância em relação às demais.

Os subgrupos 2B e 2D representam as cultivares locais, todas com sementes pretas. É interessante observar que, com exceção das de origem andina (36 BRMP, 39 BR, 45 MO, 62 MO e 42 AM) agrupadas nos subgrupos $1 \mathrm{~A}$ e $1 \mathrm{~B}$, todas as outras cultivares locais, mesoamericanas, ficaram juntas e independentes das cultivares comerciais, que compõem o subgrupo 2C (Figura 1).

De modo geral, o grau de similaridade encontrado, tanto entre as cultivares comerciais quanto entre as locais, representa reduzida variabilidade molecular em relação ao uso de RAPD. No entanto, esta situação se contrapõe com a diversidade de características morfológicas e agronômicas observadas entre estes genótipos. Isto pode ser atribuído à pressão de seleção artificial a que são submetidos, seja pelos melhoristas, nas cultivares comerciais, ou pelos próprios agricultores, nas cultivares locais. Por sua vez os marcadores bioquímicos e moleculares não têm efeito direto sobre o fenótipo da planta, por isso não são afetados diretamente pelo processo de seleção (Vera et al., 1999).

O fato de cultivares locais e comerciais mesoamericanas terem ficado separadas, embora com relativa alta similaridade, ressalta o potencial de utilização de cultivares locais em programas de melhoramento. Cruzamentos entre cultivares andinas e mesoamericanas também poderiam maximizar a variabilidade genética do germoplasma em uso no Rio Grande do Sul, além de possibilitar a exploração de nichos de mercado, disponibilizando cultivares com variados padrões de coloração e tamanho de sementes.

\section{Conclusões}

1. Marcadores RAPD são eficientes ao agrupar cultivares de feijão de acordo com o centro de domesticação.

2. Há relativamente pouca divergência entre cultivares locais de feijão, e entre estas e cultivares comerciais.

3. Cultivares comerciais de feijão, em cultivo no Rio Grande do Sul, apresentam alto grau de similaridade.

\section{Referências}

ALVAREZ, M. T.; SÁENZ DE MIEIRA, L. E.; PÉREZ DE LA VEGA, M. Genetic variation in common and runner bean of the Northern Meseta in Spain. Genetic Resources and Crop Evolution, Dordrecht, v. 45, p. 243-251, 1998.

BAI, Y.; MICHALS, T. E.; PAULS, P. Determination of genetic relationships among Phaseolus vulgaris populations in a conical cross from RAPD marker analyses. Molecular Breeding, Dordrecht, v. 4, p. 395-406, 1998.

BEEBE, S. E.; OCHOA, I.; SKROACK, P.; NIENHUIS, J.; TIVANG, J. Genetic diversity among common bean breeding lines developed for Central America. Crop Science, Madison, v. 35, p. 1178-1183, 1995.

BEEBE, S.; SKROCH, P. W.; TOHME, J.; DUQUE, M. C.; PEDRAZA, F.; NIENHUIS, J. Structure of genetic diversity among common bean landraces of Middle America origin based on correspondence analysis of RAPD. Crop Science, Madison, v. 40, p. 264-273, 2000.

CATTAN-TOUPANCE, I.; MICHALAKIS, Y.; NEEMA, C. Genetic structure of wild bean populations in their South-Andean center of origin. Theoretical and Applied Genetics, New York, v. 96, p. 844-851, 1998.

DUARTE, J. M.; SANTOS, J. B. dos; MELO, L. C. Genetic divergence among common bean cultivars from different races based on RAPD markers. Genetics and Molecular Biology, Ribeirão Preto, v. 22, n. 3, p. 419426, 1999.

EICHENBERG, K.; GUGERLI, F.; SCHNELLER, J. J. Morphological and molecular diversity of Swiss common bean cultivars (Phaseolus vulgaris L. Fabaceae) and their origin. Botanica Helvetica, Besel, v. 110, n. 1, p. 61-67, 2000.

FERREIRA, M. E.; GRATTAPAGLIA, D. Introdução ao uso de marcadores moleculares em análise genética. 3. ed. Brasília: Embrapa-Cenargen, 1998. 220 p. 
FRANCO, M. C.; CASSINI, S. T. A.; MONTRAZZI, F. C.; TSAI, S. M. RAPD analysis of common bean (Phaseolus vulgaris L.) cultivars and evaluation of common bacterial blight (CBB) and wild fire (WF) resistance. Annual Report of Bean Improvement Cooperative, East Lansing, v. 41, p. 143-144, 1998.

GEPTS, P.; BLISS, F. A. Phaseolin variability among wild and cultivated common beans (Phaseolus vulgaris L.) from Colombia. Economic Botany, New York, v. 40, n. 4, p. 469-478, 1986.

GEPTS, P.; OSBORN, T. C.; RASCA, K.; BLISS, F. A. Phaseolin-protein variability in wild forms and landraces of the common bean (Phaseolus vulgaris L.): evidence for multiple centers of domestication. Economic Botany, New York, v. 40, n. 4, p. 451-468, 1986.

GONZÁLEZ, A.; LEÓN, J. A. W.; SALINAS, A. D.; GEPTS, P. Determination of genetic diversity among wild and domesticated beans using inter simple sequence repeats (ISSRs). Annual Report of Bean Improvement Cooperative, East Lansing, v. 41, p. 99-100, 1998.

HALEY, S. D.; MIKLAS, P. N.; AFANADOR, L.; KELLY, D. Random amplified polymorphic DNA (RAPD) marker variability between and within gene pools of common bean. Journal of the American Society for Horticulture Science, Alexandria, v. 119, p. 122-125, 1994.

HARLAN, J. R.; DE WET, J. M. J. Toward a rational classification of cultivated plants. Taxon, Berlin, v. 20, p. 509-517, 1971.

JOHNS, M. A.; SKROCK, P. M.; NIENHUIS, J.; HINRICHSEN, P.; BASCUR, G.; MUNOS-SCHICK, C. Gene pool classification of common bean landraces from Chile based on RAPD and morphological data. Crop Science, Madison, v. 37, p. 605-613, 1997.

LOARCE, Y.; GALLEGO, R.; FERRER, E. A comparative analysis of the genetic relationship between rye cultivars using RFLP and RAPD markers. Euphytica, Wageningen, v. 88, p. 107-115, 1996.

MIENIE, C. M. S.; HERSELMAN, L.; TERHLANCHE, R. E. RAPD analysis of selected common bean (Phaseolus vulgaris L.) cultivars from three African countries. South
African Journal of Plant and Soil, Pretoria, v. 17, n. 2, p. 93-94, 2000.

NIENHUIS, J.; TIVANG, J.; SKROCH, P.; SANTOS, J. B. Genetic relationships among cultivars and landraces of lima bean (Phaseolus lunatus L.) as measured by RAPD markers. Journal of the America Society for Horticultural Science, Alexandria, v. 120, n. 2, p. 300306, 1995.

RODRIGUES, L. S. Caracterização e divergência genética de cultivares de feijão (Phaseolus vulgaris L.). 2001. 92 f. Dissertação (Mestrado em Fitomelhoramento) - Universidade Federal de Pelotas, Pelotas, 2001.

ROHLF, F. J. NTSYS-pc numerical taxonomy and multivariate analysis system: version 1.7. New York: Exeter Software, 1992. 236 p.

SINGH, S. P.; GUTIERREZ, J. A.; MOLINA, A.; URREA, C.; GEPTS, P. Genetic diversity in cultivated common bean - II: marker based analysis of morphological and agronomic traits. Crop Science, Madison, v. 31, p. $23-$ 29, 1991a.

SINGH, S. P.; NODARI, R.; GEPTS, P. Genetic diversity in cultivated common beans - I: allozymes. Crop Science, Madison, v. 31, p. 19-23, 1991 b.

VASCONCELOS, M. J. V.; BARROS, E. G. de; MOREIRA, M. A.; VIEIRA, C. Genetic diversity of the common bean Phaseolus vulgaris L. determined by DNA based molecular markers. Revista Brasileira de Genética, Ribeirão Preto, v. 19, p. 447-451, 1996.

VERA, C. M.; PAREDES, M. C.; BECERRA, V. V. Estudio comparativo de diversidad morfológica, isoenzimatica y RAPDs dentro y entre clases comerciales de fréjol chileno (Phaseolus vulgaris L.). Agricultura Técnica, Santiago, v. 59, n. 4, p. 247-259, 1999.

VILARINHOS, A. D.; VIDIGAL, M. C.; BARROS, E. G. de; PAULA JÚNIOR, T. J. de; CRUZ, C. M.; MOREIRA, M. A. RAPD-PCR characterization of varieties of the common bean (Phaseolus vulgaris L.) used to identify races of anthracnose fungus (Colletotrichum lindemuthianum). Revista Brasileira de Genética, Ribeirão Preto, v. 18, p. 275-280, 1995. 